\title{
KM, culture and compromise: interventions to promote knowledge sharing supported by technology in corporate environments
}

Hazel Hall, Napier University

School of Computing, Napier University, Edinburgh, UK

Melanie Goody, KPMG LLP

KPMG LLP, London, UK

Correspondence to: Dr Hazel Hall, School of Computing, Napier University, Edinburgh EH10 5DT, Scotland, UK.E-mail: h.hall@napier.ac.uk.

\section{Abstract}

The theme of knowledge sharing is discussed extensively in the knowledge management literature. Such work tends to focus on the barriers that impede knowledge sharing activity. Of these "culture" is commonly cited as a major obstacle. This article examines what is meant by the term "culture". In the context of efforts to promote good practice in knowledge management, $i$ is argued that straightforward reference to culture as barrier to knowledge sharing is inadequate. Rather, firms should be looking at power issues and, in particular, organisational politics to explain success and failure in attempts to motivate knowledge sharing. The domain of sociotechnical studies is considered as a means of unpicking cultural issues at work in specific environments through the deployment of actor-network theory to identify shifting organisational power relationships.

Keywords: actor-network theory; knowledge management; knowledge sharing; organisational behaviour; power issues; sociotechnical studies

Journal of Information Science, @ CILIP 2006 


\section{Introduction}

The topic of knowledge sharing is well established in the knowledge management literature [1, p. 1]. Successful knowledge sharing is most readily associated with three outcomes:

- improved organisational learning (for example, [2]);

- new knowledge creation and innovation (for example, [3]);

- knowledge reuse (for example, [4, p. 67, 95]).

Other research has explored the role of knowledge sharing in more specific contexts such as, for example, the facilitation of outsourcing agreements [5].

A body of work concerned with the means of motivating knowledge sharing practice (for example, [1]) is allied with the discussion of the benefits sought from effective knowledge sharing. Typically, however, the focus of papers on this topic falls on barriers to knowledge sharing, rather than enabling factors. In addition, a reading of this work would suggest that the most significant barrier to effective knowledge sharing is culture. From a practitioner's point of view, explanations that cite culture as the main determinant of the success of knowledge sharing initiatives are problematic, even if they are valid. The main problem is that the analysis of what "culture" comprises lacks sufficient detail. Added to this, it is only now that technologies implemented to enhance knowledge sharing (such as intranets) have matured that researchers and practitioners are able to reflect on the factors of their success or failure. As a result, it is still relatively difficult to devise practical strategies to improve organisational knowledge sharing practice on the basis of what is reported in the professional or academic press.

In this article it is argued that culture is cited as a catchall category to account for failed efforts to promote knowledge sharing within organisations. As such, the term is too frequently deployed to mask real, and often politically sensitive, explanations. To understand the main cultural barriers to knowledge sharing, practitioners need to assess what is actually meant by the term culture in the context of knowledge management. Action points that can be incorporated into wider strategies for improved knowledge sharing practice can be identified through the process of unpicking the term. The academic domain of sociotechnical studies offers a means of analysing relevant scenarios. Of particular interest is recent work that has deployed actor-network theory as a tool for data analy sis in a number of case study organisations. 


\section{$\mathrm{KM}$, culture and compromise: interventions to promote knowledge sharing supported by technology in corporate environments}

\section{Failure to deliver on expectations: the impact of the local environment}

It is well known that the optimism associated with the development of systems to promote knowledge sharing in the 1990s proved to be misguided. Consider this case reported by Huysman and De Wit in 2002 [4]. A large distributed organisation became interested in knowledge management in the mid-1990s. A national intranet was implemented as the focus for knowledge sharing activity. In turn, the national intranet formed part of the organisation's global intranet. Control of individual resources on the intranet was decentralised and, by 1997, much of its management was in the hands of a set of staff appointed as knowledge managers. After fours years in post these staff were frustrated by low general interest in knowledge sharing amongst their colleagues, the majority of whom were preoccupied with billable client work, and regarded the intranet simply as a basic information store.

Cases centred on the deployment of earlier technologies present similar scenarios. For example, a study from the early 1990s revealed numerous difficulties in introducing new technologies into decentralised firms, especially when they aimed to change established work practices related to knowledge sharing [6]. Those managing the process had high expectations that a technical implementation would be adopted by employees as a knowledge sharing tool. However, the professional staff at the firm prioritised the generation of reve nue through billable client work, and they were reluctant to risk future career success through sharing their knowledge with others.

These two reports hint that the context in which it is hoped that knowledge sharing will be engendered - in these two cases environments where making money through charging clients for services - is stronger than the technology and staff provided for the support of knowledge sharing activity. Evidence from such cases, whether formally reported in the literature, or simply communicated between conference delegates, validates a seam of argument that has been running through the academic domain of sociotechnical studies since the late 1970s. Over twenty years ago Kling and Scacchi [7] showed how the operation and enhancement of computer implementations are compromised by the complexities of shifting technical and social relationships. However, it is rare that practitioners are aware of this body of academic work, nor are they able to benefit from the findings of the studies, when designing systems for activities such as knowledge sharing. This article's purpose is to help identify underlying explanations for organisational culture's power to compromise knowledge sharing efforts. It does this by taking into account findings from empirical studies. 


\section{Technologies, culture and power}

Kling and Scacchi's work of 1979 [8] and 1982 [7], and the research of others who have followed their approach in their own sociotechncial studies, help explain why culture is so powerful in determining the success, or otherwise, of organisational initiatives. These accounts make particular reference to developments which involve technology, and so are relevant to knowledge sharing initiatives in large, distributed organisations. In short, this body of work argues that the way that systems are embedded within complex social relationships restricts the degree to which users can exploit them. Problems are evident when innovations in service delivery ignore the social contexts and history of the organisations in which they are situated. In particular, difficulties arise when it is assumed that:

- those who develop, or become users of, a system will always act in a rational manner (as opposed to working according to specific, personal, short-term agendas);

- the initiative will be adequately resourced in terms of infrastructural support (for example, time to develop the service to an acceptable standard prior to release);

- those involved in the development will command sufficient social and political power within the organisation to motivate its widespread adoption.

For these reasons it is often not until the post implementation stage that organisations realise the degree of support required for new technical developments. Equally, at this late stage original plans are observed as overoptimistic in terms of projected time-scales, costs, predicted usage and savings. This is not to say that these studies argue that human and organisational factors are routinely ignored in systems design. Rather, the criticisms are levelled at the way that such factors are treated as a set of organisational issues separate from technical problems.

To address this, a set of alternative assumptions should be adopted [7, p. 8]. Systems should be regarded as:

- more than a set of neutral technical components;

- a form of social organisation;

- $\quad$ subject to limitations of available resources (for example, financial investment, political power, staffing) for which they have to compete (for example, with other computer systems).

In addition, it should be appreciated that any formal articulation of their features is inadequate as a guide to what a system can do, or how it will be used. Taking account these new assumptions makes it easier to predict how the system will be adopted. This is because technical change can be accepted as embedded within numerous other 


\section{$\mathrm{KM}$, culture and compromise: interventions to promote knowledge sharing supported by technology in corporate environments}

activities. In addition, it is made obvious that the outcomes of the technical change are subject to the actions of those involved in it, as well as the history of related changes within the organisation. It can be seen that when developing a technology for organisational adoption it is not enough to simply deal with equipment: complex institutional negotiations are also required.

Organisational theorists with interests in technologies have recently made similar arguments about systems design and the role of the context in which an implementation is placed. For example, Ciborra [9] argued that traditional models of systems design and implementation do not recognise the power of technical and human agents as actors. This is evident:

- when employees are observed adopting and adapting systems in unanticip ated ways (termed "bricolage") [9] p. 49];

- in the consequential shifts in the technology's deployment $[9$, p. 88];

- in the way that organisations serve as a kind of "host" to technology that plays the role of "guest" [9, p.116].

With reference to knowledge-sharing in particular, a number of researchers now consider the inadequacies of blaming culture for failed initiatives without reference to organisational power-bases. Kling, working with Ekbia in 2003 [10], made a call to examine power as an explanatory factor of knowledge-sharing practice. Indeed, the authors challenge the broad explanation of culture as the reason why knowledge-sharing initiatives fail in organisations. They maintain that by invoking the term "culture", it is possible to hint at issues of power without addressing specific power relationships [10, para 49]. Researchers have been urged to examine the issue of culture at a deeper level to make sense of the influence of power relationships within organisations [10, para 1].

A number of methods can be adopted to trace power relationships within an organisation. One tool of analysis deployed in sociotechnical studies is actor-network theory. Developed in the 1980s, largely through the work of Callon and Latour (for example, [11], [12]), it is favoured in studies of technologies, not least because both humans and non-humans (for example, technologies, documents) are regarded as "actors" within the environment under investigation. The technique considers the shifting relationships between actors as members of networks that compete for organisational resources. Such resources range from the tangible, for example, office space, to the intangible, such as corporate sponsorship or organisational attention. Actor-networks grow by translating the interests of other actors as potential recruits to their way of thinking. They disintegrate when ties within the network loosen. If an organisation is envisaged as a mesh of competing actor-networks, it is possible to relate successes and failures in corporate initiatives to the degree to which particular groups enhance or diminish their organisational power-base. Thus actor-network theory is appropriate to studies of knowledge sharing practice to 
trace the impact of organisational culture in cases where the term "culture", in reality, refers to issues related to the influence of organisational power. Deployed in such a way, the technique aids researchers in their quest to examine service delivery with reference to the social and historical context of the organisation in which it is situated. It is then possible to provide an explanation of the outcomes of an implementation at a level of detail that goes beyond simply naming culture as the dominant factor.

\section{Actors, power balances and impacts in a knowledge management actor network}

Some examples given below show how it can be useful to consider knowledge management implementations through the examination of actor-networks. These analyses point to reasons why knowledge management is often misunderstood, and how efforts to promote knowledge sharing can be thwarted, in a corporate environment, with due acknowledgement to shifting power-bases.

In a large, distributed organisation with an established interest in knowledge management, membership of an actor-network focused on knowledge management will be broad. Human actors are likely to include:

- Specialist knowledge management staff in a central unit

- Specialist knowledge management staff distributed across business units

- Senior staff whose responsibilities include knowledge management, but who are not knowledge management specialists themselves

- Senior sponsors of knowledge management across the or ganisation

- "Ordinary" staff across the organisation whose work contributes to knowledge management efforts

If there has been significant input to the development of the knowledge management strategy at the organisation, external human actors may be important members of the network. So, for example, an external consultant brought in to help establish communities of practice, or a systems vendor who supplied the IT infrastructure to support knowledge sharing in the organisation, may merit inclusion in a diagrammatic representation of the knowledge management actor-network.

Non-human actors who contribute to the network may comprise: 


\section{$\mathrm{KM}$, culture and compromise: interventions to promote knowledge sharing supported by technology in corporate environments}

- documents, for example: the organisation's stated knowledge management policy; minutes of meetings at which knowledge management is discussed; published instructions on how "ordinary" staff should contribute to meeting knowledge sharing objectives, intranet usage statistics;

- technology artefacts, such as the organisation's intranet and its constituent components, for example repositories, shared collaboration space;

- concepts, for example: knowledge management, knowledge sharing.

At any point in time, an actor- network can be drawn as a simple chart. The chart might be impressionistic. For example, it may be formulated quickly on the basis of everyday familiarity with the actor-network. In contrast, for a piece of academic research, such a chart would be the output of a data analysis exercise based on extensive evidence systematically gathered from the field. In the example given below relative power of individual actors within the network is represented by how close they are positioned to the centre of the diagram. The weight of the lines which link the actors shows the strength of their shared relationships.

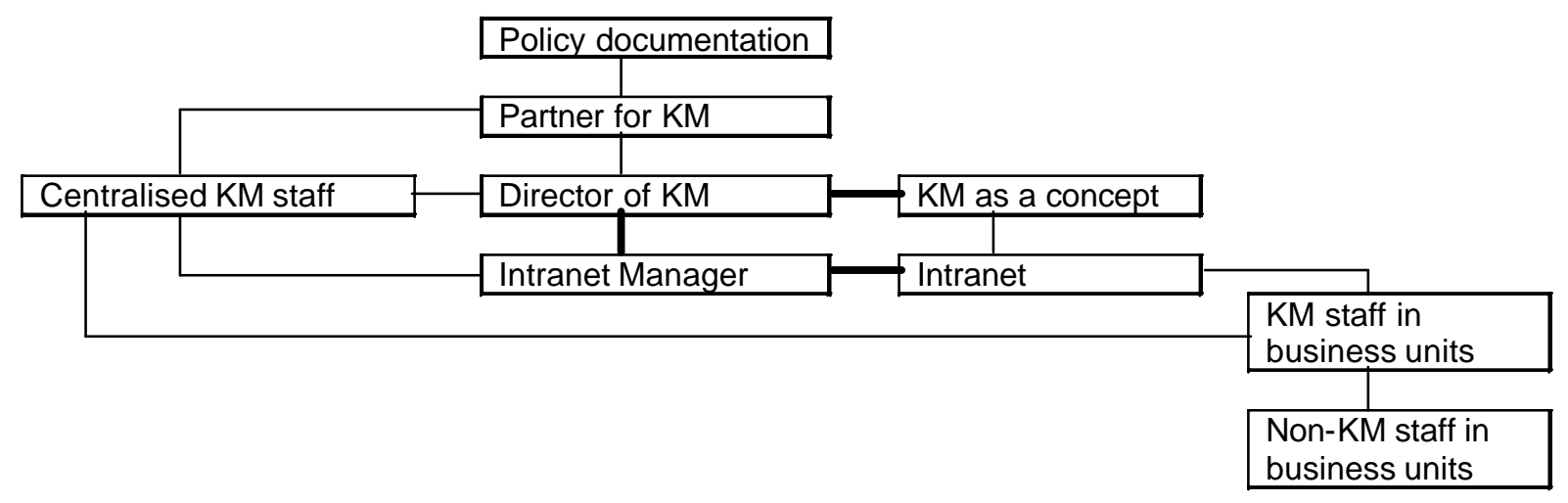

A set of actor-network diagrams that chart the relative positions of the actors over a period of time is particularly useful for observing power shifts.

A common complaint amongst knowledge management practitioners is that knowledge management as a concept is misunderstood. Confusion as to what knowledge management represents to an organisation accounts in part for difficulties in promoting its causes. An actor-network analysis may point to possible reasons for confusion in an individual organisation by highlighting the relative power of actors within the network. The following explanations may be appropriate:

- The main artefact of the knowledge management implementation, for example an intranet, may have been promoted very strongly in its early stages. An unintended consequence of this is that actors at the extremes of 
the knowledge management actor-network equate knowledge management with technology. They are blind to the idea that the technology is merely a support for an activity that relies on a number of strategies for its success. This notion may be reinforced through undue emphasis on other non-human actors in the network. For example, intranet usage statistics may be used as a proxy for the measurement of knowledge management activity. This might be a good political move for some purposes, such as continued investment in the intranet, but does not help a cause that wishes to promote knowledge management as a set of organisational activities beyond uploading and searching for information on an intranet.

- Policy documentation may be too weak in the actor-network, and thus ignored, with the result that a large proportion of staff have not had the opportunity to learn what knowledge management comprises. Alternatively the policy documentation may be too strong. For example, bold statements of the future promise of knowledge management may have raised expectations in the past. The failure for these highprofile expectations to be delivered leads to confusion as to the purposes of investment in knowledge management programmes.

- The position and behaviours of staff whose job titles indicate a knowledge management role influence nonspecialists' perceptions of what knowledge management comprises. For example, if designated knowledge management staff operate as low level administrators who would rather not take on additional responsibilities, it is likely that knowledge management will be seen as a non-critical support activity. It is also possible that knowledge management will be equated with information management. As a result of this, non-specialists may regard knowledge management as a passing management fad, or an attempt to glamorise basic information management work.

- Where the main players in the actor-network share a common background the organisation risks an undue focus on a particular aspect of knowledge management. For example, in organisations where the strongest actors hold qualifications in library and information science, it is likely that the knowledge management implementation will be one based on codification, with knowledge sharing for the purpose of information reuse prioritised over organisational learning, and new knowledge creation and innovation.

A further point to consider is that actor-networks do not exist in isolation. They compete with other actornetworks for members, and all actor-networks are competing for a limited amount of organisational resources. If an actor-network is not successful in keeping or enhancing its membership, its power-base weakens. Thus, in turn does the opportunity to promote its messages. So, for example, if knowledge management staff in a large distributed organisation feel greater loyalty to the business unit in which they are based, or associate with other knowledge management staff from remote business units, rather than those in the centralised function, the knowledge management actor-network starts to fragment. A fragmented actor-network finds it difficult to voice its message when its own staff have effectively joined competing networks, or created new ones.

Perhaps the most obvious competing networks for large commercial organisations are those centred around earning client revenue. If individuals' salaries and career success depends on the money generated by their business units, it is not surprising that they would prioritise memberships of actor-networks associated with their 


\section{$\mathrm{KM}$, culture and compromise: interventions to promote knowledge sharing supported by technology in corporate environments}

primary job function over any other. Similarly, if the core business of a company is centred around a particular professional group - for example accountants and tax specialists in a professional services company, or technical experts in an IT consultancy - these "professionals" are almost certainly bound to command more power as individuals, and in their own actor-networks, than anyone located outside this group. Their loyalty to their own networks is manifest in failure to adopt corporate systems for knowledge sharing, and adherence to local ad hoc practice. As a consequence, knowledge management practitioners have to recognise that they are committed to promoting knowledge sharing in "imperfect" environments.

\section{The compromise: promoting knowledge sharing in "imperfect" environments}

It has been established that citing "culture" as an explanatory factor for failed knowledge sharing initiatives is inadequate. If the term culture is considered instead as "power relationships", it is possible to make a better judgement on what aspects of culture are inhibiting knowledge management efforts. One way of conducting such an analysis is to deploy actor-network theory to identify how the message of what knowledge management is, and what it can achieve, is thwarted within the organisational context. Then strategies might be implemented to address problems (that it is actually possible to address) by those leading the knowledge management programme within the organisation.

It is evident that in the four scenarios provided above - (1) too great an emphasis on the artefact of a KM implementation; (2) too great or too little attention paid to knowledge management policy documentation; (3) low-level "behaviours" of staff in designated KM roles; (4) group-think amongst those primarily responsible for knowledge management in the firm - action could be taken to correct some of the misconceptions surrounding knowledge management. For example, knowledge management staff could be encouraged to devise means of promoting their work as more than an administrative burden. However, it is worth recognising that some circumstances are impossible to alter. For example, in an organisation that trades on the qualifications of a specific set of professional staff, employees with professional qualifications that are not directly related to the revenue-generating activity are unlikely to enjoy a similar level of status. This means that they are not well placed to encourage their colleagues to comply with their wishes. For example, knowledge management staff find it difficult to persuade accountants to adopt corporate-wide tools for knowledge sharing.

It is therefore important for knowledge management practitioners to recognise the degree to which the organisational power of the knowledge management function can be enhanced. Equally, it is necessary to devise strategies to compensate for circumstances that are difficult, or impossible, to change, such as the perception of 
knowledge management as a fad of the late 1990s. Conscious of the limits of the knowledge management function's organisational influence, knowledge management practitioners can seek to strengthen the message to knowledge share in the firm using methods that are less obvious than those usually promoted in the professional press. These methods should be deployed with the goal of strengthening the knowledge management actornetwork. This approach is evident in firms where knowledge management may have "disappeared" as a separate function, yet knowledge management is still firmly on the corporate agenda. Compromises may need to be made, for example over job titles of knowledge management staff, especially in instances where the term "knowledge management" has become tainted. Quasi-subversive strategies include manoeuvring the knowledge management function into a position where the reporting lines tie closely to the main business of the firm, for example locating it within the sales and marketing function, rather than "support" services such as IT. In strengthening the political position of knowledge management, the broad knowledge management actor-network is bolstered. As a result, calls to promote knowledge sharing are likely to be louder and more readily heeded. A further technique for knowledge management practitioners to adopt, and one that applies specifically to information systems such as intranets, is to welcome multi-channel knowledge sharing rather than complain, for example, that no one contributes to intranet repositories. Such systems can therefore be valued in their roles as non-human actors that connect others for the purposes of off-line knowledge sharing.

\section{Conclusion}

This article has argued that to blame organisational culture for the failure of knowledge sharing initiatives in firms is too simplistic. Academics working in the domain of sociotechnical studies have shown that, in this context, the term culture is deployed as a euphemism for power issues. By mapping the main players in their firm's knowledge management actor-network, knowledge management practitioners are able to create a visual representation of knowledge management's main allies within their organisations. This may go some way to explain why certain messages about knowledge management are not heard, nor heeded, in the firm. It may be possible to address some of the issues that account for the knowledge management actor-network's strength (or weakness) as compared with other internal actor-networks. However, it is often the case that knowledge management's position, and that of its main adherents, is not powerful enough to effect positive change, for example to promote knowledge sharing, following the techniques advised in the popular knowledge management business press. In these circumstances, strategies that accept a degree of compromise, sometimes in the form of behaviour that may appear subversive in the eyes of the knowledge management community, may be the most effective. 
$\mathrm{KM}$, culture and compromise: interventions to promote knowledge sharing supported by technology in corporate environments

\section{References}

[1] H. Hall, Input friendly intranets: motivating knowledge sharing across intranets, Journal of Information Science, 27(3) (2001) 139-146.

[2] B.A. Huberman and T. Hogg. Communities of practice: performance and evolution (Xerox Palo Alto Research Center, Palo Alto, CA, 1994)

[3] O. Janssen, Job demands, perceptions of effort-reward fairness and innovative work behaviour, Journal of Occupational and Organizational Psychology 73 (2000) 287-302.

[4] M. Huysman and D. De Wit. Knowledge sharing in practice (Kluwer, London, 2002).

[5] T. Kern and L. Willcocks,. Exploring information technology relationships: theory and practice, Journal of Strategic Information Systems 9(4) (2000) 321-350.

[6] W.J. Orlikowski. Learning from notes: organizational issues in groupware implementation. In R. Kling (ed.), Computerization and controversy: value conflicts and social choices (2nd ed.). (CA Academic Press, San Diego, 1996, pp. 173-189).

[7] R. Kling and W. Scacchi, W, The web of computing: computer technology as social organization, Advances in Computers 21 (1982) 1-90.

[8] R. Kling and W. Scacchi, Recurrent dilemmas of computer use in complex organizations. Proceedings of the National Computer Conference, New York, 38 (1979) 107-116.

[9] C. Ciborra. The labyrinths of information. (Oxford University Press, Oxford, 2002).

[10] H. Ekbia and R. Kling. Power issues in knowledge management (2003). Available at: http://rkcsi.indiana.edu/archive/CSI/WP/WP03-02B.html (accessed 24 March 2006).

[11] M. Callon, Some elements of a sociology of translation: domestication of the scallops and fishermen of St Brieuc Bay. In J. Law (ed.), Power, action and belief: a new sociology of knowledge? (Routledge, London, 1986, pp. 196-133).

[12] M. Callon and B. Latour, Unscrewing the big Leviathan: how actors macrostructure reality and how sociologists help them to do. In K. Knorr Cetina \& A. Cicourel (eds.), Advances in social theory and methodology: towards an integration of micro and macros sociologies (London, Routledge, 1981, pp. 277-303).

Journal of Information Science, ( CILIP 2006 